\title{
Has Loyalty to Online Grocery Retailers Declined? An Abstract
}

\author{
Giang Trinh
}

\begin{abstract}
This paper investigates behavioral loyalty of consumers to online grocery retailers over time. The study uses consumer packaged goods data from the UK, one of the most advanced online retailing countries. The data contains actual consumer repeat purchasing of three product categories (soft drinks, toothpaste, and cat food) from four major grocery retailers (Tesco, Asda, Sainsbury's, and Waitrose) operating online from 2005 to 2014. Using three measures of behavioral loyalty (share of category requirement, repertoire size, and polarization index), the study finds that consumer loyalty to online retailers has declined from 2005 to 2009 and remained stable from 2010 to 2014.
\end{abstract}

G. Trinh $(\bowtie)$

Ehrenberg-Bass Institute, University of South Australia, Adelaide, SA, Australia

e-mail: Giang.Trinh@marketingscience.info 